\title{
The spatiotempora variations rules of Songzao coal mining subsidence based on numerical simulation
}

\author{
J. Lu ${ }^{1,2}$, Y. Li ${ }^{1,2}$, H. Cheng ${ }^{3}$, and Z. Tang ${ }^{1,2}$ \\ ${ }^{1}$ Key Laboratory of Exogenic Mineralization and Mine Environment, Institute of Geology and Mineral \\ Resources, Chongqing 400042, China \\ ${ }^{2}$ Research Center of State Key Laboratory of Coal Resources and Safe Mining, Chongqing 400042, China \\ ${ }^{3}$ Energy College, Chongqing 400041, China
}

Correspondence to: J. Lu (lujiahao09@mails.ucas.ac.cn)

Published: 12 November 2015

\begin{abstract}
With the increasing demand of coal, coal mining at Songzao makes the area of land subsidence growing larger. Land subsidence in coal mining area not only made large subsided farmland out of production and caused the enormous loss to local agricultural production, but also brought a number of serious problems to the local social economy and ecology Environment. To use Probability-integral Method based on numerical simulation of Songzao Mine, its subsidence simulation data from 1999 to 2009 was obtained. Hence, overlay analysis between Goaf data and the simulation data in 2009, and between field investigation and the simulation data in 2009 were carried out. After the coal mining underground was identified as the crucial cause of surface subsidence. Therefore, the accuracy and feasibility of the simulation data had been verified, and the spatial pattern and spatiotemporal variations conforming to the actual values have been obtained. The results show five main findings. The first indicated that the surface subsidence is mostly located at the top of the Goaf, where the overlap areas between Goaf data and subsidence simulation data have accounted for $93.05 \%$ of Goaf and $65.19 \%$ of subsidence simulation data respectively. The second finding indicated that by end of 2009 , the mining subsidence extent had reached about $5087.50 \mathrm{hm}^{2}$. This area accounts for about $40 \%$ of total of the mining area. The third finding indicated that within 10 years from 1999 to 2009, the influence range of subsidence has expanded about $2340.54 \mathrm{hm}^{2}$, and the coal mining subsidence rate in Songzao Mine has increased gradually with time. Moreover, average increasing speed of the extent area in the second five years was larger than the first five years (about $75.08 \mathrm{hm}^{2} \mathrm{yr}^{-1}$ more). The fourth finding indicated that maximum subsidence has increased from $2.0 \mathrm{~m}$ in 1999 to $2.5 \mathrm{~m}$ in 2004 , and then $3.0 \mathrm{~m}$ in 2009 with subsidence rate of about $0.1 \mathrm{~m} \mathrm{yr}^{-1}$. At the same time, the area affected by the subsidence $2.0 \mathrm{~m}$ in 1999 was more than twice the area affected by subsidence in 2004. This in return, it was more than 7 times larger than the area affected by subsidence in 2009 of the one affected by subsidence in 2004. Extent of the area affected by the $2.5 \mathrm{~m}$ subsidence has also enlarged rapidly. This area has expanded by about 40 times in 2009 than its value in 2004. In addition, the area of subsidence of value $3.0 \mathrm{~m}$ has reached about $0.44 \mathrm{hm}^{2}$ in 2009 from zero value. Finally, the fifth finding indicated that the overall extend of the mining subsidence was much more serious in southern than in northern side of the Songzao Mine. Moreover, it was indicated that the increasing rate of mining subsidence in the western side of the study area was as bigger as in the eastern side between 1999 and 2009. The spatiotemporal variations rules of songzao coal mining subsidence based on numerical simulation could provide reference for the subsequent subsidence prevention and land consolidation.
\end{abstract}




\section{Introduction}

Coal is currently the most important source of energy in China. It accounts for more than $70 \%$ of the total energy production and consumption. Development of the coal industry not only promoted the development of other industries, but also caused a series of environmental problems, especially due to land subsidence caused by coal mining, that is causing damage to the regional ecological environment and ecological structure (e.g. He et al., 1994; Luo and Chen, 1994; Wu et al., 1997; Holzer, 1985; Guerrero et al., 1999; Sheoey et al., 2000; Hou and Zhang, 2004; Xia et al., 2008). According to incomplete statistics, when coal mining was about $1.0 \times 10^{4} \mathrm{t}$, the average land subsidence area was about $0.3 \mathrm{hm}^{2}$. The land subsidence area caused by national coal mining was more than $7.5 \times 10^{5} \mathrm{hm}^{2}$ (e.g. Chen et al., 2002). Moreover, this area is increasing by an annual rate of $2.7 \times 10^{4} \mathrm{hm}^{2}$ (Lin and Wang, 2005). This, in fact, may lead to imbalance between the current coal exploitation and ecological environment protection. Although mining subsidence governance work is being highly valued, the effect of subsidence governance increases is not obvious because the lack of overall planning and investment management. In this paper, subsidence due to coal mining is investigated using numerical simulation for Songzao Mine. In addition, overlay analysis between simulation data and Goaf data was performed to prove that the coal mining was the main cause for subsidence. This is done after accuracy and feasibility checks of the simulation results were verified through the site under investigation. Then, the spatial patterns and temporal variation of Coal Mining Subsidence was obtained, which could provide reference for the subsequent subsidence.

\section{General situation of Songzao Mine}

Songzao Mine (Fig. 1) is located in Qijiang District of Chongqing City, China. According to the plan in 2005, its mine planning production capacity is $10800 \mathrm{kt} \mathrm{yr}^{-1}$, with basic reserves $1685768 \mathrm{kt}$, and recoverable reserves of $931282 \mathrm{kt}$. With continuous exploitation, mining subsidence continues. In addition, the Goaf becomes larger during the long process of mining exploitation. This, in fact, is causing serious damages and local scale problems (e.g., crack or subsidence in surface, water dewatering, drying up farmland, infrastructure damage, secondary geological disasters, soil erosion). This is also leading to ecological environmental deterioration as well as seriously negative impacts affecting the mining economic development and social stability. For example, the collapse basin had a huge impact on land especially arable land in its formation process. The chief influence is cracks or caves in houses and roads, and slopes, cracks, puddles, uneven and so on in arable land. Then under the combined effects of rain, wind and other factors, the phenomenon of soil erosion such as soil damage, move, deposition and so on show up day by day, accelerating surface erosion, resulting in cultivated soil degradation, and finally declining in the quality of cultivated soil (e.g. Chen et al., 1999). A survey shows that Mining Goaf in Songzao mine had damaged farmland about $3466.74 \mathrm{hm}^{2}$, farming production in dry land yields decreased $20-30 \%$, and farming production in paddy fields turned into dry land reduced by more than $50 \%$. Parts of the badly damaged fields forced to be fallow. This seriously damaged the land resources. At the end of 2008 , about $1500 \mathrm{hm}^{2}$ of paddy fields converted to dry land in Songzao mining subsidence, and the indirectly affecting area was actually much larger than the data (Yang and Li, 2011). It requires that the spatiotemporal variations rules of coal mining subsidence should be found and then an effective long-term mechanism to the protection of farmland and damaged farmland reclamation should be established.

\section{Numerical simulation of mining subsidence}

At present, the widely used numerical method of China's mining subsidence areas is Probability-integral Method, which has advantages as parameters easy to determine, serviceability and so on (e.g. Ling et al., 1999; Gu and Hong, 2012). For example, Gu and Hong (2012) applied it based on MATLAB to do research about Ningtiaota Mine in the mountains, and achieved a multi-parameter nonlinear curve fitting expression which accurately describes the collapse rules in the surface after shallow coal seam mining. Gu and Gao (2011) used it to carry out the simulation and prediction of Xiangyang Coal mining subsidence in the hilly area, analyzed the dynamic collapse process for mining and provides reference in decision-making for post-mining subsidence prevention, remediation and recovery. Tan et al. (2006) also utilized it to research the uneven subsidence in the surface, tilt and curvature change by taking the geological conditions in a coal mine in Chongqing as the background condition, and then better achieved the ground subsidence influence evaluation on the building and construction. This paper also used it based on the soft MSPS independently developed by Mining Damage and Protection Research Institute of China University of Mining and Technology to achieve numerical simulation of Subsidence in Songzao, and then the result was used to analyze the spatiotemporal variations of Songzao Coal Mining Subsidence.

\subsection{Probability-integral method}

Probability-integral Method is a numerical method based on Stochastic Medium Theory. It has been widely used in the research field of mining subsidence in China, and its model (e.g. He et al., 1994) is as follows,

$W_{\mathrm{ex}}=\frac{1}{r} e^{-\pi \frac{x^{2}}{y^{2}}}$,

where $r$ is the radius of the main impact area. 


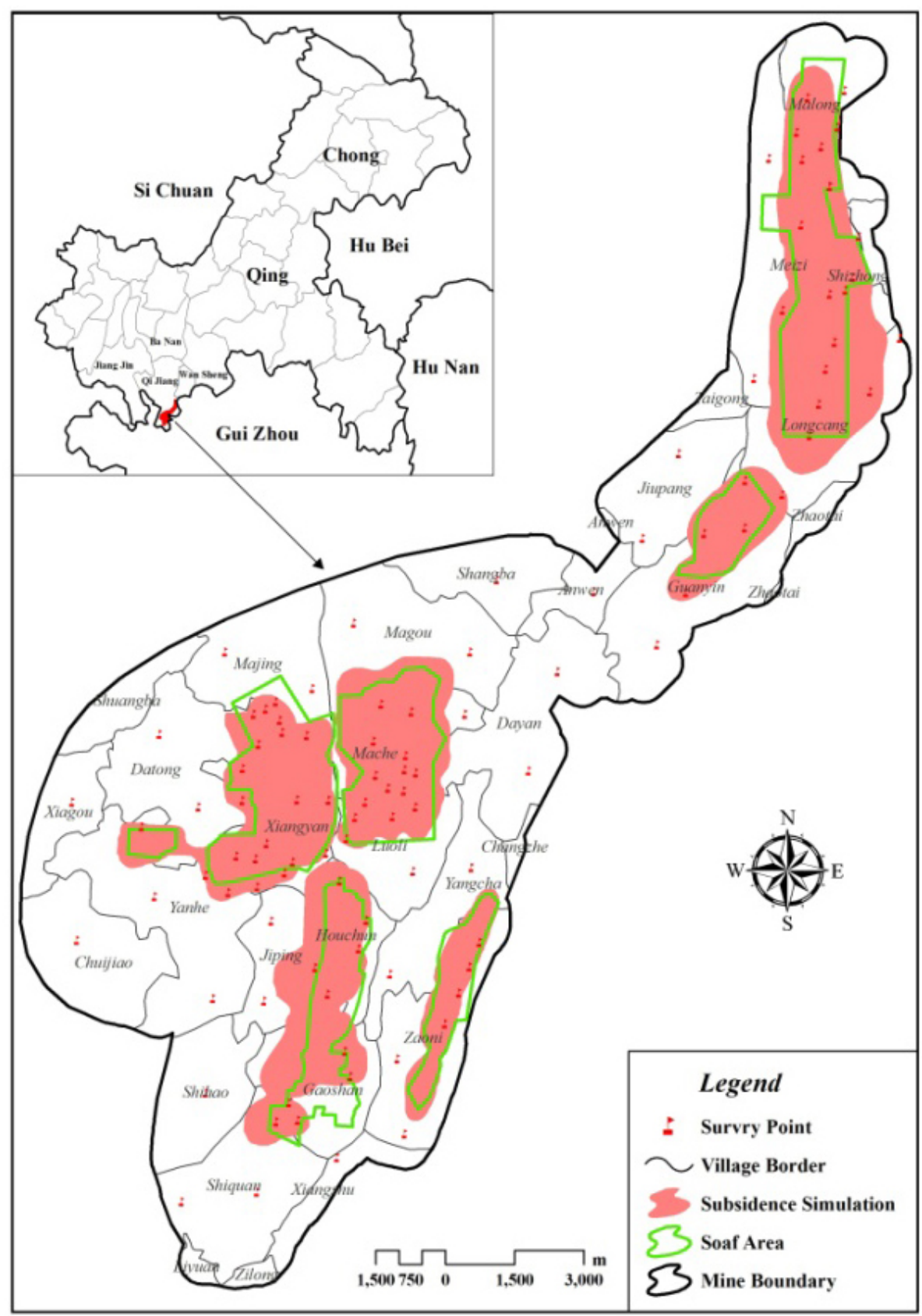

Figure 1. Location and overlay analysis map.

Table 1. The statistics of overlay analysis.

\begin{tabular}{ccccc}
\hline $\begin{array}{c}\text { Goaf } \\
\left(\mathrm{hm}^{2}\right)\end{array}$ & $\begin{array}{c}\text { Mining subsidence numerical } \\
\text { simulation }\left(\mathrm{hm}^{2}\right)\end{array}$ & $\begin{array}{c}\text { Overlap area } \\
\left(\mathrm{hm}^{2}\right)\end{array}$ & $\begin{array}{c}\text { Overlap area/mining subsidence } \\
\text { numerical simulation }(\%)\end{array}$ & $\begin{array}{c}\text { Overlap area/mining subsidence } \\
\text { numerical simulation }(\%)\end{array}$ \\
\hline 3554.93 & 5073.80 & 3307.83 & 65.19 & 93.05 \\
\hline
\end{tabular}




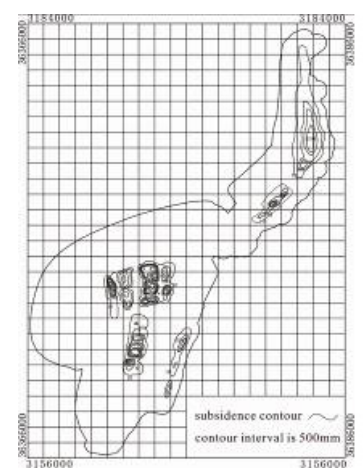

1999

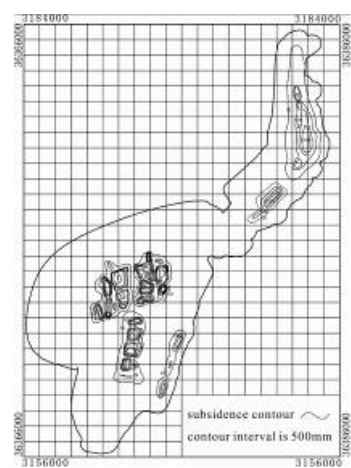

2004

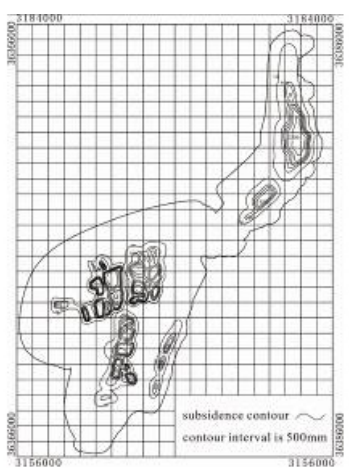

2009

Figure 2. The subsidence contour of Songzao coal mining area.

1. $W(x, y)$ is the subsidence value of any surface point $(x$, $y$ ), and its computational formula shows as follows:

$W(x, y)=\frac{1}{W_{0}} W^{0}(x) W^{0}(y)$,

$W^{0}(x)=\frac{W_{0}}{2}\left[\operatorname{erf}\left[\frac{\sqrt{\pi}}{r} x\right]-\operatorname{erf}\left[\frac{\sqrt{\pi}}{r}(x-L)\right]\right]$,

$W^{0}(y)=\frac{W_{0}}{2}\left[\operatorname{erf}\left[\frac{\sqrt{\pi}}{r_{1}} y\right]-\operatorname{erf}\left[\frac{\sqrt{\pi}}{r_{2}}(y-L)\right]\right]$,

$W_{0}=m q \cos \alpha$,

where $W^{0}(x)$ is the subsidence value of the point whose abscissa is $x$ on the movement/trend main sectional plane when critical extraction took place in the incline direction. $W^{0}(y)$ is the subsidence value of the point whose ordinate is $y$ on the incline main sectional plane when critical extraction took place in the trend direction. $m$ is the mining thickness. $q$ is the subsidence coefficient. $\alpha$ is dip angle of coal seam. $L$ is the length calculation of trend and tendency of limited mining under considering the displacement distance of inflection point. $r, r_{1}, r_{2}$ respectively is the radius of the main impact area of trend, downhill and uphill. erf is Gaussian error function.

2. The incline value, the curvature value, horizontal movement, horizontal displacement of any surface point along the tilt direction $\varphi$ should be respectively calcu- lated through formulas as follows:

$$
\begin{aligned}
& i(x, y, \phi) \\
& =\frac{1}{W_{0}}\left[i^{0}(x) W^{0}(y) \sin \phi+i^{0}(y) W^{0}(x) \sin \phi\right], \\
& K(x, y, \phi) \\
& =\frac{1}{W_{0}}\left\{\left[k^{0}(x) W^{0}(y)+k^{0}(y) W^{0}(x)\right]\right. \\
& \left.\quad \sin ^{2} \phi+i^{0}(x) i^{0}(y) \sin ^{2} \phi\right\}, \\
& U(x, y, \phi) \\
& =\frac{1}{W_{0}}\left[U^{0}(x) W^{0}(y) \cos \phi+U^{0}(y) W^{0}(x) \sin \phi\right], \\
& \varepsilon(x, y, \phi) \\
& =\frac{1}{W_{0}}\left\{\varepsilon^{0}(x) W^{0}(y) \cos ^{2} \phi+\varepsilon^{0}(y) W^{0}(x) \sin ^{2} \phi\right. \\
& \left.\quad+\left[U^{0}(x) i^{0}(y)+U^{0}(y) i^{0}(x)\right] \sin \phi \cos \phi\right\},
\end{aligned}
$$

where $i^{0}(x), k^{0}(x), U^{0}(x), \varepsilon^{0}(x)$ is respectively the incline value, the curvature value, horizontal movement, and horizontal displacement on the trend main sectional plane of any surface point $(x, y)$ when the critical extraction along the $\varphi$ direction. At the same time, $i^{0}(y)$, $k^{0}(y), U^{0}(y), \varepsilon^{0}(y)$ is respectively the incline value, the curvature value, horizontal movement, and horizontal displacement on the incline main sectional plane of the same point $(x, y)$.

3. When subsidence was caused by more than one workplane, the total influence of those should be considered to overlay analysis in the simulation process.

4. Three known values should be used to solve coordinate conversion in the Numerical simulation process. They are corresponding data that had been converted through Probability-integral Method from the point's coordinate 
$\left(\mathrm{X}_{0}, Y_{0}\right)$ in the bottom left corner of work-plane and the trend direction azimuth $\alpha$. When one point's coordinate value $(X, Y)$ in geodetic coordinate system (left-handed coordinate system) or other independent coordinate system (right-handed coordinate system) required be converted to the calculating (right-handed coordinate system) as $\left(\mathrm{X}_{j}, Y_{j}\right)$, the formula as follows should be used:

$\left[\begin{array}{c}X_{j} \\ Y_{j}\end{array}\right]=\left[\begin{array}{cc}\cos \alpha & \sin \alpha \\ \sin \alpha & -\cos \alpha\end{array}\right]\left[\begin{array}{cc}X-X_{0} & Y-Y_{0}\end{array}\right]$

\subsection{Numerical simulation and analysis of its result}

According to Regulations of buildings, water, railway and main well lane leaving coal pillar and press coal mining, the $10 \mathrm{~mm}$ subsidence contour was taken as boundary line in the study area. And then after numerical simulation of mining subsidence of the study area, the subsidence contour map (Fig. 2) and the corresponding statistical data (Table 2) in 1999, 2004 and 2009 was respectively obtained.

\subsubsection{Overlay analysis and proof}

Through summarizing and arranging the data of geology and mineral maps, engineering plane maps and surfaceunderground contrast plans, the Goaf data was obtained with the area about $3554.93 \mathrm{hm}^{2}$ in 2009 . Then the overlay analysis was respectively carried out between Goaf data and subsidence simulation results in 2009 , field investigation and subsidence simulation results in 2009. The results (Fig. 1 and Table 1) showed that

1. the 70 field investigation points located in the extent of coal mining subsidence numerical simulation data had showed the same subsidence phenomenon as the simulation data, and these points also displayed the location as at the top of or close to the Coal Goaf. And the other 48 points unlocated in the simulation had not obviously appeared subsidence phenomenon in 2009. It could primely prove subsidence simulation data accord with the actual and the accuracy and feasibility of the simulation results was verified.

2. The surface subsidence mostly located at the top of the Goaf area.

3. The overlap areas between Goaf data and subsidence simulation results were totally about $3307.83 \mathrm{hm}^{2}$, accounting respectively for $93.05 \%$ of mining Goaf and $65.19 \%$ of subsidence simulation results. In short, the results inferred that coal mining was the basic and crucial driven factor for surface subsidence.
Table 2. The area statistics of mining subsidence numerical simulation.

\begin{tabular}{rrrr}
\hline $\begin{array}{c}\text { Subsidence } \\
\text { value }(\mathrm{mm})\end{array}$ & $1999\left(\mathrm{~m}^{2}\right)$ & $2004\left(\mathrm{~m}^{2}\right)$ & $2009\left(\mathrm{~m}^{2}\right)$ \\
\hline 10 & 27469616 & 37295259 & 50875011 \\
500 & 11779468 & 17304094 & 26613164 \\
1000 & 6085552 & 9925673 & 18444527 \\
1500 & 2818673 & 4863881 & 11717092 \\
2000 & 517273 & 1155490 & 7818101 \\
2500 & 0 & 58014 & 2234698 \\
3000 & 0 & 0 & 4375 \\
\hline
\end{tabular}

\subsubsection{Analysis of simulation result}

Through comparative analysis of the three periods of numerical simulation data and field investigation, the results (Fig. 2 and Table 2) were obtained as follows:

1. The extent of Coal Mining Subsidence in Songzao from 1999 to 2004 expanded about $982.56 \mathrm{hm}^{2}$. When the extent was expanding in every direction and overall impact to the surrounding, the trend in north and southwest was more prominent.

2. The extent of Coal Mining Subsidence in Songzao from 2004 to 2009 expanded about $1357.98 \mathrm{hm}^{2}$. In the five years, each subsidence extent expansion accelerated significantly, especially the area of sink depth $2.0 \mathrm{~m}$ was fastest in the horizontal direction, and the west was fastest in the horizontal direction. And the subsidence foreign expansion feed is significantly higher, especially from the space dimension, the fastest subsidence foreign expansion feed distributed in the subsidence contour $2.0 \mathrm{~m}$. When the extent was expanding in every direction, the trend in west was most prominent in the five years.

3. The extent of Coal Mining Subsidence in Songzao from 1999 to 2009 expanded about $2340.54 \mathrm{hm}^{2}$. The maximum subsidence depth changes from $2.0 \mathrm{~m}$ in 1999 to $2.5 \mathrm{~m}$ in 2004 , and then having increased to $3.0 \mathrm{~m}$ in 2009. At the same time, the extent of $2.0 \mathrm{~m}$ in $2004 \mathrm{ex}-$ panded by about 2 times than that in 1999, and then it is 7 times in 2009 to 2004 . The extent of $2.5 \mathrm{~m}$ had enlarged rapidly, and its area expanded by about 40 times in 2009 than that in 2004 . The extent of $3.0 \mathrm{~m}$ had grown out of nothing, and its area was about $0.44 \mathrm{hm}^{2}$.

\section{Conclusions and discussion}

Songzao mine is rich in coal resources, but it is located in exposed bedrock mountainous with complex terrain. The surface subsidence caused by coal mining is greatly different from the plains, such as it has mountain surface moving characteristics and bedrock bare mountain surface particularity 
movement. Through comparative analysis of the three periods of numerical simulation data and overlay analysis data, the realistic simulation results were obtained and then the mining subsidence spatiotemporal variations rule was drawn as follows:

1. The subsidence simulation data was realistic and the accuracy and feasibility of the simulation results was verified. Because the 70 field investigation points located in the extent of coal mining subsidence numerical simulation data had showed the same subsidence phenomenon as the simulation data, and these points also displayed the location as at the top of or close to the Coal Soaf. And the other 48 points unlocated in the simulation had not obviouslly appeared subsidence phenomenon in 2009.

2. The surface subsidence mostly located at the top of the Goaf, because the overlap areas between Goaf data and subsidence simulation data accounted respectively for $93.05 \%$ of Goaf and $65.19 \%$ of subsidence simulation data. All of the field investigation points especially those located in subsidence simulation areas could well prove subsidence simulation results was realistic. In short, it can be inferred that coal mining is the basic and crucial driven factor for surface subsidence.

3. Overall, the mining subsidence extent showed as that was much more serious in southern than northern, and the increasing rate of mining subsidence unfolded as much bigger in western than eastern from 1999 to 2009.

4. The coal mining subsidence rate increased gradually with time, and the increasing rate was significantly bigger than the previous post. The impact of coal mining subsidence range expanded from $2746.96 \mathrm{hm}^{2}$ in 1999 to $3729.52 \mathrm{hm}^{2}$ in 2004 , and then increased to $5087.50 \mathrm{hm}^{2}$ in 2009 accounting for about $40 \%$ of total area of the mining area. At the same time, the average increasing speed of extent area was bigger in the second five years than the first five years about $75.08 \mathrm{hm}^{2} \mathrm{yr}^{-1}$.

5. The maximum subsidence depth of Songzao Mine increased with time, and the extent of each subsidence depth also expanded. In addition, the expanding speed of extent area was gradually accelerated over time. The maximum subsidence depth turned from $2.0 \mathrm{~m}$ in 1999 to $3.0 \mathrm{~m}$ in 2009 , with subsidence depth increasing rate about $0.1 \mathrm{~m} \mathrm{yr}^{-1}$.

6. In the underground mining process of Songzao Mine, surface is prone to concentrate deformation, and then deformation bands appeared damage. The maximum exploitation of ground movement caused by coal mining is bigger than it in plains under the same conditions, and the range of surface movement is also relatively larger. But due to Songzao Mine located in Hilly area with complex geology and varied topography, the same surface subsidence deformation is not obvious as in plains. Coupled with the some uncertainty of the nature and mechanism of underground rock, the surface subsidence of coal mining is a constantly changing tectonic processes. Therefore, more and better research of Goaf subsidence rules should be developed with longterm tracking and monitoring, and investment in research subsidence area of governance should also be increased in order to achieve sustainable use of land resources in subsidence areas. As a result, the greatest harmony and unity among economic, social and ecological benefits could be created.

Acknowledgements. This study was supported by the Non-profit Industry Financial Program of Ministry of Land and Resources of China(Grant200911015-04)and Science and Technology Planning Project of Chongqing Municipal Bureau of Land Resources and Housing Management (Grant CQGT-KJ-2014004).

\section{References}

Chen, L., Deng, K., and Zhao, Z.: Space variation rules of physical characteristics about farmland soil due to mining subsidence, J. China Coal Soc., 24, 586-590, 1999.

Chen, L., Guo, D., Xu, S., Li, J., and Zhang, Y.: A study on state and comprehensive control ways of subsided land of Yanzhou coal mining area in China, J. Nat. Resour., 17, 504-508, 2002.

Gu, J. and Gao, Z.: Application of Probability-integral Method in the Prediction of Mining Subsidence, Mine Surveying, 2, 47-49, 2011.

$\mathrm{Gu}$, S. and Hong, X.: Application of probability integral surface movement prediction method in mountainous area with shallow coal seam, J. Xi' an Univ. Sci. Technol., 1, 45-50, 2012.

Guerrero, O., Rudolph, D. L., and Cherry, J. A.: Analysis of longterm land subsidence near Mexico City: field investigations and predicative modeling, Water Resour. Res., 30, 3327-3341, 1999.

He, G., Yang, L., Ling, G., Jia, F., and Hong, D.: Mining subsidence Theories, China Mining Univesity Press, Xuzhou, China, 12-156, 1994.

Holzer, T. L.: Land Subsidence: Its Impacts And Costs In The U.S., Underground Space, US Geological Survey (USGS), Reston, VA, USA, 9, 1985.

Hou, Z. and Zhang, Y.: Movement rules of coal mining subsidence surface ground in Datong Mining Area, Coal Sci. Technol., 32, 50-53, 2004.

Lin, Z. and Wang, G.: Remediation of Subsided Land and Creation of Constructed Wetland in Mining Area - A case of Remediation of Subsided Land in Xuzhou Mining Area, J. Nat. Resour., 20, 790-795, 2005.

Ling, G., Wu, K., and Zhang, Z.: A Research on Analysis Method of Mining Subsidence Parameters for Space Problem and Its Application, J. China Univ. Mining Technol., 23, 64-69, 1999.

Luo, Z. and Chen, Q.: Research on Density Stability of Air Dense Medium Fluidized Bed, J. China Univ. Mining Technol., 4, 6270, 1994. 
Sheoey, P. R., Loui, J. P., Singh, K. B., and Singh, S. K.: Ground subsidence observation and a modified influence function method for complete subsidence prediction, Int. J. Rock Mech. Min., 37, 801-811, 2000.

Tan, Z., Hu, P., Cheng, W., Wang, X., Wang, Y., and Fu, S.: Safety evaluation of the ground surface subsidence under the condition of the seam group expbitation, J. Safety Sci. Technol., 2, 101104, 2006.

Wu, K., Hu, Z., and Chang, J.: Distribution Rules of Ground Crack Induced by Coal Mining, J. China Univ. Mining Technol., 26, 56-59, 1997.

Xia, Y., Du, R., and Sun X.: Relative analysis and regressive estimation of mining subsidence in Tongchuan Mining Area, Coal Sci. Technol., 36, 89-92, 2008.

Yang, G. and Li, Y.: Effects of Coal Mining Subsidence on Environment in Songzao Mining Area and Land Reclamation, J. Anhui Agricult., 39, 20487-20489, 2001. 